University of Nebraska - Lincoln

DigitalCommons@University of Nebraska - Lincoln

Faculty Publications, Department of Psychology

Psychology, Department of

May 1970

\title{
Positive and negative prejudice: Interactions of prejudice with race and social desirability
}

Richard A. Dienstbier

University of Nebraska-Lincoln, rdienstbier2@unl.edu

Follow this and additional works at: https://digitalcommons.unl.edu/psychfacpub

Part of the Psychiatry and Psychology Commons

Dienstbier, Richard A., "Positive and negative prejudice: Interactions of prejudice with race and social desirability" (1970). Faculty Publications, Department of Psychology. 121.

https://digitalcommons.unl.edu/psychfacpub/121

This Article is brought to you for free and open access by the Psychology, Department of at DigitalCommons@University of Nebraska - Lincoln. It has been accepted for inclusion in Faculty Publications, Department of Psychology by an authorized administrator of DigitalCommons@University of Nebraska - Lincoln. 


\section{Positive and negative prejudice: Interactions of prejudice with race and social desirability ${ }^{1}$}

\section{Richard A. Dienstbier ${ }^{2}$, University of Rochester}

While dictionary definitions of the term prejudice often indicate either positive or negative bias, the use of the term in the social sciences has been largely restricted to indicating negative biases, the information available on positive racial bias, or positive prejudice, is minimal. Apparent examples of the phenomenon of positive racial bias are becoming relatively common, however. For example, when a university begins actively to recruit black students whose academic credentials would not normally be acceptable, then a specific instance of positive racial discrimination is occurring, possibly indicating a form of positive racial prejudice.

Those studies which bear on positive prejudice were designed to examine the influence of ethnic attitude on reasoning. Prentice (1957) found that subjects scoring in the lower quartile of ethnocentrism and fascism scales demonstrated bias in favor of certain ethnic groups in a syllogistic reasoning task by accepting syllogisms favorable to certain ethnic groups more than comparable but racially neutral syllogisms. In a similar study, Schuman and Harding (1964) found a tendency for highly antiprejudiced subjects to accept a larger number of irrational but positive statements than of irrational but negative statements (when each type was paired with a rational statement of opposite sign), leading the authors to conclude that there were individuals who demonstrated "love prejudice."

The problem of various definitions of prejudice goes beyond the simple issue of positive or negative bias, the great variability of definition at the operational level has resulted in problems in the inter-

${ }^{1}$ Special thanks are due Vincent Nowlis and Edward E. Ware for advice and encouragement in the planning and writing of these studies.

2 Presently at the University of Nebraska. pretation of specific studies and in a lack of closure on some of the issues which have received attention in the recent literature. The various studies designed to investigate the belief theory of prejudice (Rokeach, Smith, \& Evans, 1960), for example, have employed an array of different scales and behavioral measures between them as indices of prejudice. This variety of dependent measures has caused problems in comparing the results of the various studies. Triandis (1964) has indicated, for example, not only that there is often a great deal of difference in social distance indicated toward a stimulus individual on different measures but that across different subject populations different factors emerge on such scales. Triandis's work has strongly indicated that it is potentially more useful to operationalize prejudice as a pattern of discrimination on a variety of scales Following these suggestions from the research of Triandis, for the purpose of the studies reported in this paper, prejudice was viewed in terms of discrimination patterns on a number of scales

The purpose of the studies of this paper was to investigate positive prejudice, with an eye toward underlying dynamics. Positive Negro prejudice was defined (for a specific issue) as existing when a Negro stimulus individual received less negative discrimination on a specific social distance dimension than a comparable white stimulus individual.

Although the first of the two studies reported below was not begun in order to investigate positive prejudice, the results were particularly interesting insofar as they pertained to positive prejudice. Only those aspects of the results which directly relate to positive prejudice are emphasized in this paper. The second study reported herein was designed to investigate positive prejudice directly, and those results are presented in total.

Since the hypotheses of the second study were partially based on the results of the first study, a preview of the results of that first study, as they pertain to the second, is necessary. It was noted that the factorial design of race by personality valence of Study I allowed the direct comparison of social distance type ratings of the same stimulus personality with different racial labels, and that for the socially desirable stimulus personality, appreciable and significant positive prejudice toward $\mathrm{Ne}$ groes existed on several scales. The second study was performed with a group of subjects who were known to be relatively liberal in their social-political viewpoint. For the second study, it was hypothesized that 
individuals demonstrating positive prejudice, as defined above, would be on the highly liberal end of attitude scales pertaining to war, crime, and rioting and that such individuals would be low in dogmatism and rigidity as measured by standard personality tests of those variables. Those hypotheses were derived from the extensive literature on authoritarianism starting with Adorno, Frenkel-Brunswik, Levinson, and Sanford (1950). That research has indicated that conservative or punitive social attitudes and tendencies to be rigid and dogmatic are often associated with negative racial prejudice. The hypotheses of Study II were based on the assumption that the personality correlates which are normally associated with negative racial prejudice will be negatively related to positive prejudice. That hypothesis is also related to hypotheses suggested by Keniston (1967) that student liberalism, related to personality characteristics of flexibility and open-mindedness, is characterized by identification with the oppressed.

\section{STUDY I}

Subjects

Subjects were 80 male juniors from a Jesuit high school in a suburb of Rochester, New York; 78 of the subjects were white, and 2 were Negro. The scaling of the parents' occupations on the Warner, Meeker, and Eels (1949) index indicated that generally the subjects were from the middle range of the middle class.

The subjects were not volunteers, three entire classes which would normally have received regular instruction during that time were used.

\section{Procedure}

Design. Each subject read and evaluated two personality profiles, one of which was Negro, one white. One of the profiles pertained to a stimulus person who had beliefs and values of high social desirability (the John profile), while the other profile described a stimulus person with characteristics generally low in social desirability (the Jack profile). Subjects who were presented the desirable profile as that of a white person evaluated the undesirable profile as that of a Negro, the other half of the subjects received the remaining two race-personality combinations. Order, defined as whether the profile was rated first or second, was counterbalanced so that each profile-race combination appeared first in half the booklets and second in half. A $2 \times 2 \times 2$ factorial analysis of variance design was thus effected, with two levels each of order, race, and social desirability, and with each subject seeing two of the four personality-race combinations. The effects of race, personality, and order, and the triple interactions were therefore within-subject differences in the analyses of variance of the scales; the three two-way interactions were all between-subject effects.

The personality profiles. The personality profiles were introduced by instructions which indicated that the evaluations were part of a study in interpersonal liking and that the persons who were to be evaluated were real people. Emphasis was placed on the desirability of answers reflecting real honesty, subjects were assured that no identification with their own answers would be required, and none were.

The profiles were each approximately 200 words in length. That of the individual with positive values (John) depicted a likable and socially successful high school junior who was college bound upon his graduation, and whose ideas were "a lot like those of most people his age." The sketch of the negative individual (Jack) described a 17-yearold high school dropout who was a somewhat greedy, shy, and rebellious social misfit whose ideas were generally "too far out for most of the other people his age."

Race was indicated by the profile title and by the phrase "is a Negro who" inserted in the first line of the profile when it pertained to a Negro stimulus person. Race was also indicated on each of the pages of scales pertaining to a given profile by a title line identical to that used with the personality sketch (e.g., "Jack B , Age 17, Negro, High School Dropout"). Each sketch, with its name, race, age, and status designation, appeared on an individual page.

Prejudice measures. The prejudice measures followed (on subsequent test booklet pages) the profile to which they pertained. The measures of prejudice or social distance toward the stimulus persons were scales taken from or related to those used in the belief theory of prejudice studies of the 1960's. The purpose of this rather wide range of scales was simply to allow comparisons between the data from a number of studies pertaining to the belief theory of prejudice.

The scale pertaining to felt similarity to the stimulus person (A in Table 1) is from Stein, Hardyck, and Smith (1965). The personal feeling measure (B in Table 1) is taken from Byrne and Wong (1962) and Byrne and McGraw (1964) and is related to the key measure used by Stein 
et al. (1965), Stein (1966), Rokeach et al. (1960), and Smith, Williams, and Willis (1967). The choice of work partner scale (C in Table 1) represented the only other prejudice measure used in the two Byrne studies cited above. The felt similarity scale was presented as a 6-point scale, the other two scales described above were presented as 9-point scales.

Sixteen behavioral differential (BD) scales were included (Davis \& Triandis, 1965) representing four of the five major prejudice factors isolated by Triandis (1964). The BD scales were in the form of 9-point scales with "would" and "would not" as the polar dimensions. The Triandis factors represented by the BD scales were formal acceptance with superordination, friendship acceptance, hostile acceptance, and interaction with superiors, the excluded factor was marital acceptance and did not apply since the stimulus individuals were the same sex as the subjects.

The directions of the scales (whether from positive to negative or negative to positive) were determined randomly.

\section{Results}

The means of the prejudice measures by personality-race condition appear in Table 1, along with the $F$ ratios resulting from analyses of variance for the individual scales and the $\mathrm{BD}$ composite score (computed as a summary score of the $16 \mathrm{BD}$ scales). All the scales were scored so that a higher numerical value represents the least prejudice or the greatest attraction. The first scale indicated in Table 1 was a 6-point scale, all the other individual scales were 9-point scales The scales were examined individually, rather than according to the factor structure established by Triandis (1964). The criteria for that decision were as follows. First, although the number of subjects rating each of the stimulus individuals was too small in relation to the number of scale items to determine a reliable factor structure, the factor structures which did appear as a result of the informal factor analyses indicated a different factor structure for each of the four stimulus individuals. The lack of either factor consistency between stimulus individuals or consistency with those factors extracted by Triandis precluded an analysis by factor scores.

The data of Table 1 indicate a large main effect for personality or social desirability differences. The more desirable profile (John) consistently and significantly received higher ratings. Generally, the desirability manipulation accounted for more variance than that of race difference.

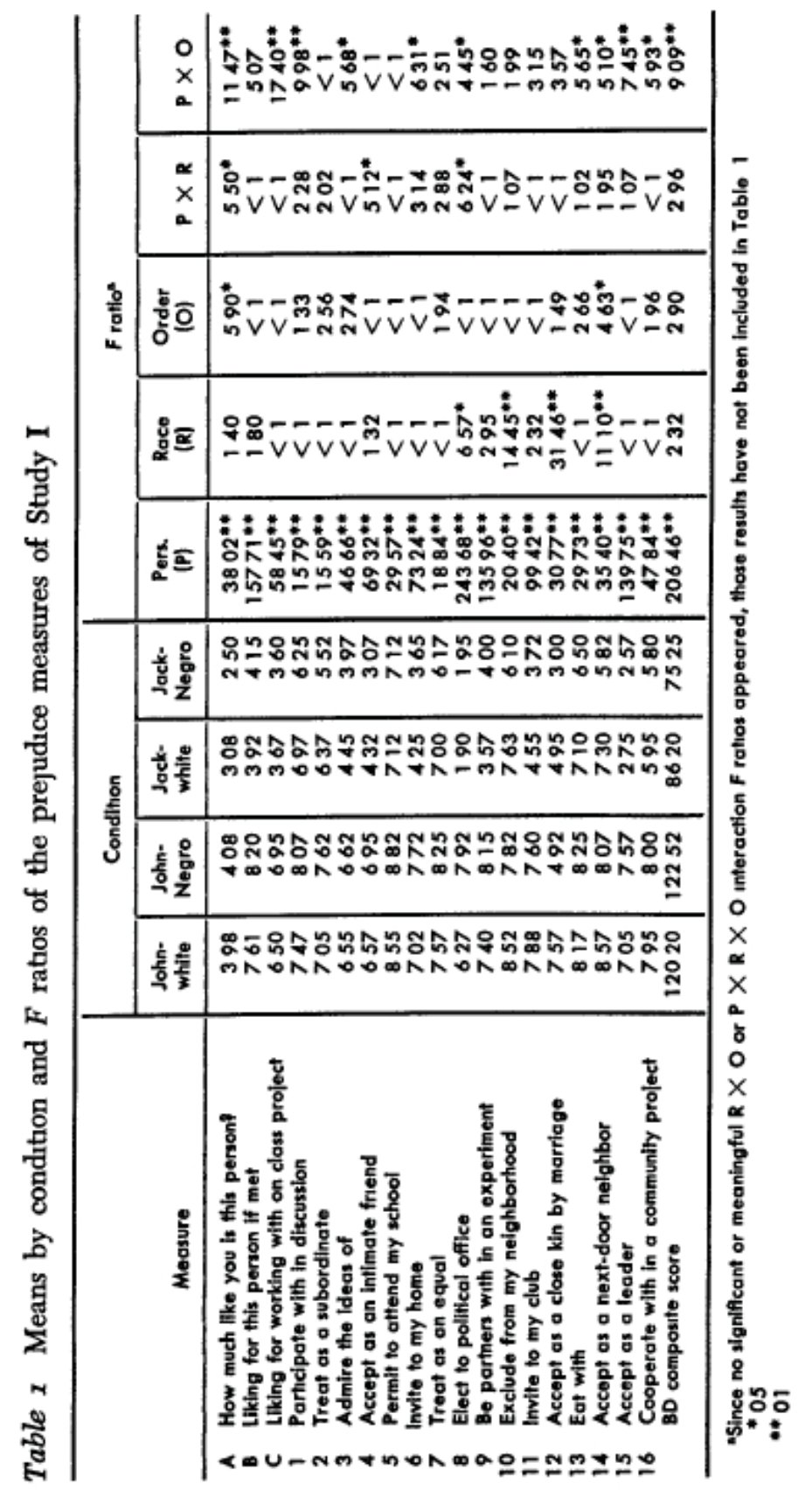


It is the interaction of race and social desirability, however, which is particularly relevant: the means figures of Table 1 indicate that at the positive profile level, of the 19 independent measures used in the study, 15 measures were given more positive ratings for the Negro stimulus person that for the white stimulus person. A high level of positive $\mathrm{Ne}-$ gro prejudice was thus demonstrated toward the personality represented by the John-Negro condition. On the other hand, at the negative profile level, 16 of the 19 scales were lower for the Jack-Negro stimulus person than for the comparable white person. Those differences indicated that positive racial prejudice was demonstrated toward the $\mathrm{Ne}$ gro at the positive personality level, while at the negative personality level, negative Negro prejudice prevailed. Considering the race-by-social desirability interactions as reflected by the $F$ ratios of Table 1 , the three statistically significant interactions generally support that conclusion. These occurred on the scales pertaining to felt similarity (A in Table 1), friendship acceptance (4), and electing to political office (8) For the elect to political office measure, positive Negro prejudice at the level of the high social desirable profile resulted not only in the significant race-by-social desirability interaction, but also in the significant main effect for race.

The order effects were all of the same type, with ratings higher for the first profile rated by the subjects; all the items except one indicated that trend, though it was statistically significant in only two instances. No ready explanation for this phenomenon can be offered at present.

All the personality-by-order interactions were similar, indicating that overall ratings for the two profiles of each subject were lower if the positive profile was presented first, and higher if the negative profile was presented first. These interactions seem to be based on the contrast between the two extremely different personality sketches. The profiles which were rated second were apparently rated more negatively (in the case of the Jack profile) or more positively (for the John profile) as a result of contrast with the preceding profile.

There were no significant race-by-order or three-way interactions.

\section{STUDY II}

\section{Subjects}

Since previous research with basic psychology students of the University of Rochester had indicated that they tended to have liberal social and racial attitudes, and since that quality was sought in the subject population for the second study, women from that course were used for Study II. Women were used in order to verify the concept of positive prejudice over a broader population.

Subjects volunteered for the study in order to fulfill a course requirement for experimental participation. Subjects had no prior knowledge of the form or nature of the experiment and participated in the study at the same time and in the same large auditorium in which their lectures were normally given. As in Study I, 80 subjects were used.

\section{Procedure}

Part I. The design of the first part of Study II was similar to that of Study I, except that the two personality sketches used were both relatively positive profiles of college sophomore girls in different colleges. Since positive prejudice occurred mainly at the high social desirability profile level in Study I, by having both personality profiles relatively positive, it was anticipated that the race-by-social desirability interactions of Study I would appear as main effects for race, indicating positive prejudice, in Study II. The first personality sketch described Sally M, a 19-year-old midwestern university sophomore who had overcome the loneliness of anonymity to become a well-liked and successful student. Sally's interests included guitar, folk singing, tennis, and reporting for the campus newspaper. The second sketch, of Joan C, described a 20 year-old Eastern college sophomore with definite academic interests in English and the social sciences. Also well liked, her outside interests included drama and being an avid college sports fan.

The same prejudice scales were used to evaluate the stimulus persons in the second study as were used in the first, race was also indicated exactly as in the previous study

Part II. In addition to the evaluations of the personality sketches, subjects in Study II encountered scales measuring the personality variables of dogmatism (Form E, Rokeach, 1960), rigidity (the GoughSanford scale, from Rokeach, 1960), and nine attitude scales pertain- 
ing to the Vietnam war, crime, and rioting. The attitude scales were written specifically for the second study, and appeared as follows

1 Bombing targets near North Vietnamese population centers in the war is justified. $(\mathrm{A})^{3}$

2 Even the limited use of atomic weapons in the Vietnam war is unacceptable. (D)

3 The participation of the U.S. in the war in Vietnam is justified. (A)

4 The recent increase in crime in the U.S. is due to laws which too greatly favor the criminal. (A)

5 Recent increases in crime in the U.S. are due to moral decay in the nation. (A)

6 Recent increases in crime in the U.S. are due to social inadequacies in American society. (D)

7 In order to prevent future riots in the cities of the U.S., it is necessary to give more aid and attention to the areas which have rioted or may riot. (D)

8. The most important reasons for the recent summer riots in the U.S. were injustices toward the Negro. (D)

9 The rioting and lawlessness which the major cities have seen in recent summers must be crushed in any way possible if they occur again. (A)

The scales used in the second part of Study II were all randomized together. They were all of the same physical form, being 6-point scales with no neutral point, the scale form was identical to that of the dogmatism scale (Rokeach, 1960). The subjects indicated agreement or disagreement with the scales by marking them with a number from +3 to -3 , representing a range from "I agree very much" to "I disagree very much. "The formal written instructions for the scales emphasized that the "best answer to each statement is your personal opinion."

Subjects were informed that the two parts of this study were different studies, in order to support that assertion, the physical appearance of the booklets and the instruction styles were different. A1though student numbers were required on both of the booklets in order to allow comparison of the two data sets, subjects were told that the numbers were required only so that they could receive credit for their experimental hour and were assured that their answers would never be associated with them personally.

\footnotetext{
${ }^{3}$ The letters following each item indicate whether agreement (A) or disagreement (D) increased the subjects' scores on the scale.
}

\section{Results}

Part I. Since all the dependent measures of the first part of Study II were identical to those of Study I, the means and the $F$ ratios of Table 2 are directly comparable to those of Table 1 . Since large differences did not exist in social desirability between the two personality profiles of Study II, it was expected that personality differences would be appreciably reduced in Study II. That expectation was confirmed, only 5 significant $F$ ratios for personality differences were indicated on the 19 measures used.

Differences on 7 of the 19 independent scales indicated significant race effects in the direction of positive prejudice, while significant negative race effects exactly duplicated similar effects from Study I, occurring only on the kin, neighborhood, and next-door neighbor scales (in Table 2, scales 10, 12, and 14). Altogether, overall positive Negro prejudice occurred on 13 of the 19 independent scales. Significant positive prejudice appeared on the personal feeling scale (B in Table 2 ), the choice of work partner scale $(C)$, and the BD scales concerning participating with in a discussion (1), admiring the ideas of (3), acceptance as an intimate friend (4), being partners with in an experiment (9), and acceptance as a leader (15).

The significant race-profile interactions on the treat as subordinate (2), treat as an equal (7), and cooperate with on a community project (16) BD scales are mainly due to relatively large differences between the Joanwhite and Joan-Negro conditions, with the Joan-white condition rated relatively lower in all cases. Thus it appears that whatever the personality flaw which the subjects saw in the Joan profile, it results in the Joan-white condition being rated lower than the other three race-profile conditions; Joan-Negro is not equally rebuffed. The significant personality differences do indicate, however, that there are some measures upon which there is no such immunity for the Joan-Negro condition. Thus both the Joan-white and Joan-Negro profiles suffer on the personal feeling measure (B) and on the BD scales of elect to political office (8), be partners with in an experiment (9), and accept as a leader (15).

The main effects for order in Study II indicated a trend opposite to that of Study I. In Study II, of the 19 independent prejudice measures, 17 indicated that personality-race combinations which were rated second were rated higher than those rated first. 


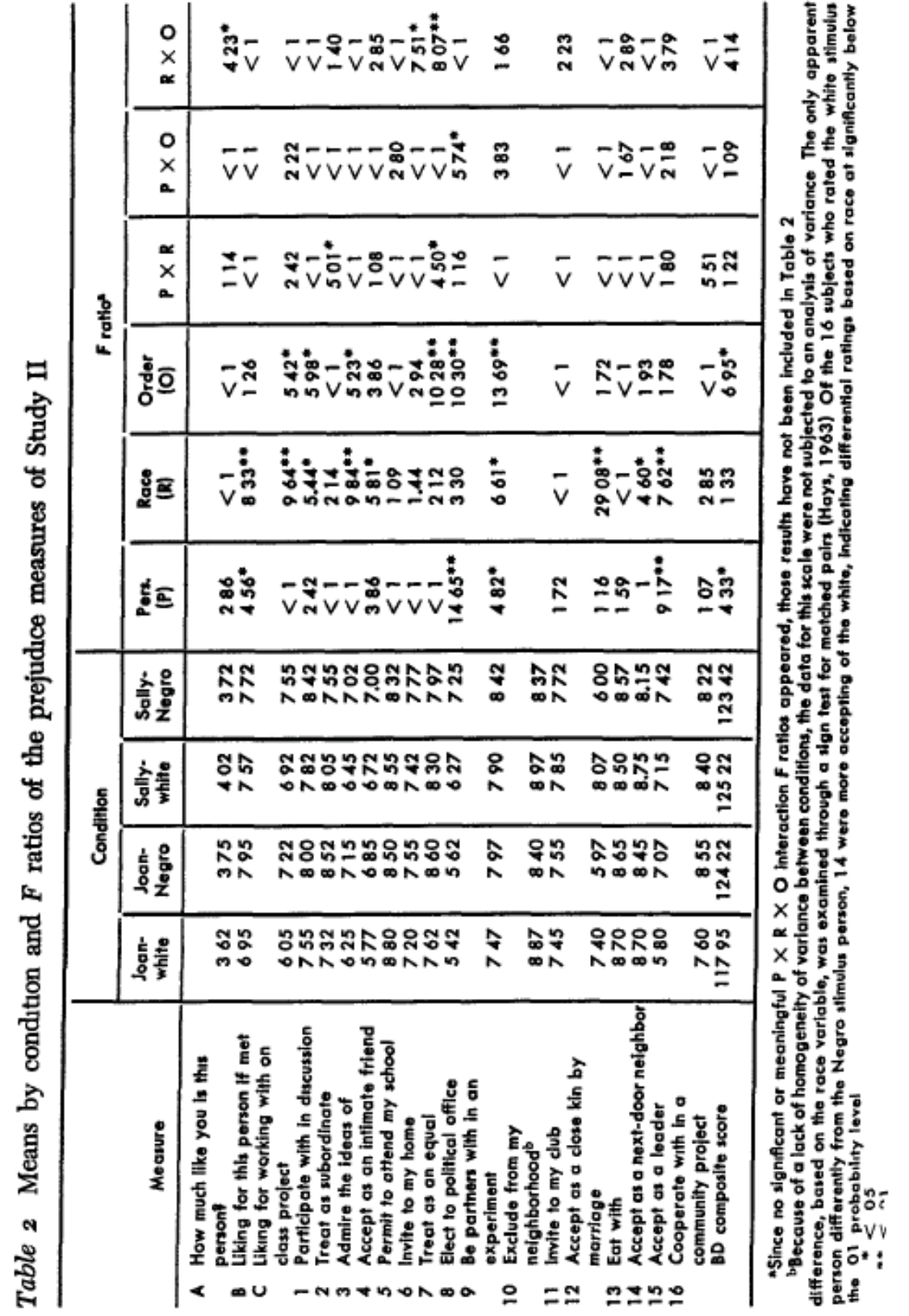

It was expected that since the personality differences in social desirability were minimized in Study II, that the order-by-personality interactions would be reduced. Generally, that prediction was verified with the appearance of only one such significant interaction in Study II.

Race-by-order interactions appeared in Study II, though none appeared in Study I, reflecting the relatively greater salience of the race variable in the second study. The significant Study II interactions were all of the same type, with ratings for the profiles higher when the Negro profiles were first than when they were second.

Although it is difficult to interpret the specific causes of some of the order effects and the order interactions described above, particularly the differences in order effects between Study I and Study II, collectively they tend to indicate that, directly or indirectly, the subjects of these studies have engaged in some sort of comparisons between profiles and that the outcome of those comparisons seemed to be dependent on profile valence and race.

Part II. It was hypothesized that the three attitude scales concerning war, crime, and riots would correlate with each other and that they would correlate positively with rigidity and dogmatism. The testing of those interrelationships was effected only to serve as a validation of the attitude scales (since they were developed for use only in this study) and of the relationships derived from research studies of authoritarianism.

Each of the scores of attitude on war, crime, and riots was composed of three individual scales, the WCR score of Table 3 was derived from the simple sum for each subject of the three single attitude scores The attitude scales were scored so that higher scores reflected a more positive attitude toward war and a more punitive attitude toward crime and riots. The correlations between the attitude scores and between the personality and attitude variables appear in Table 3 .

There is a rather strong positive relationship between both dogmatism and rigidity and conservative attitudes toward war, crime, and riots for this population. These results indicate that the predictions based on the authoritarianism syndrome and the more recent work of Keniston (1967) have been verified for these college women. This validation of the attitude scales confirms the conceptual usefulness of those scales for this study. 
Table 3 Correlations among attitude and personality varables.

\begin{tabular}{l|c|c|c|c|c}
\hline \multirow{2}{*}{ Attifude Measure } & \multicolumn{3}{c|}{ Attifude measure } & \multicolumn{2}{c}{ Personality measure } \\
\cline { 2 - 6 } & Wor & Riots & Crime & Dogmatism & Rigidity \\
\hline WCR & $86^{* *}$ & $66^{* *}$ & $74^{* *}$ & $40^{* *}$ & $46^{* *}$ \\
War & & $32^{* *}$ & $47^{* *}$ & $29^{* *}$ & $44^{* *}$ \\
Riots & & & $31^{* *}$ & .08 & $28^{* * *}$ \\
Crime & & & & $47^{* *}$ & $30^{* *}$ \\
\hline
\end{tabular}

** 01

Since both positive and negative racial prejudice have been defined in this paper in terms of differences in preference between racially different (but otherwise similar) stimulus persons, the prejudice measure used to test the relationship of prejudice to the personality variables were normalized Negro-minus-white difference scores for each subject. The particular items for which the difference scores were calculated were the $\mathrm{BD}$ composite score and the most straightforward interpersonal attraction item - the personal feeling measure (B in Table 2). ${ }^{4}$ Those scores were calculated by first normalizing the scores within personality-race conditions, but across orders. The four groups of scores were normalized with the same mean and the same standard deviations. The Negro-minus-white scores were then calculated for each subject. Since the majority of subjects in this study demonstrated positive prejudice on the two scales chosen, the simple correlation of the personality scores for each subject with the difference score was used to test the relation of positive prejudice with the attitude and personality variables. The results of those tests appear in Table 4 .

The correlations of Table 4 indicate that the hypotheses that the personality correlates of positive prejudice would be opposite from those commonly associated with negative prejudice were supported, positive prejudice correlated with a lack of dogmatism and rigidity and with more liberal attitudes on war, crime, and rioting.
Table 4 Correlations between prejudice measures and attitude and personality vanables

\begin{tabular}{|c|c|c|c|c|c|c|}
\hline \multirow[b]{2}{*}{ Prefudice measuro } & \multicolumn{4}{|c|}{ Attrtude measure } & \multicolumn{2}{|c|}{ Personality measure } \\
\hline & WCR & War & Crime & Riots & $\begin{array}{c}\text { Dog- } \\
\text { matism }\end{array}$ & Rigidity \\
\hline $\begin{array}{l}\text { Personal feeling (B) } \\
\text { BD composite score }\end{array}$ & $\begin{array}{l}-27^{*} \\
-21\end{array}$ & $\begin{array}{l}-27^{*} \\
-24^{*}\end{array}$ & $\begin{array}{l}-21 \\
-12\end{array}$ & $\begin{array}{l}-13 \\
-07\end{array}$ & $\begin{array}{l}-27^{*} \\
-26^{*}\end{array}$ & $\begin{array}{l}-35^{* *} \\
-29^{* *}\end{array}$ \\
\hline
\end{tabular}

$\begin{array}{rl}* 05 & 05 \\ * * 01 & 01\end{array}$

\section{DISCUSSION}

\section{A Note on Prejudice Measures}

As main effects, the personality and race data of these studies provide support for the criticisms of Triandis $(1961,1964)$ and Triandis and Davis (1965) concerning the relative insensitivity of simple friendship or choice of work partner measures to race manipulation. An informal comparison of these scales (B and $\mathrm{C}$ in Tables 1 and 2) with the BD scales of these studies indicates that those two scales are exceptional in their high sensitivity to social desirability differences compared to their sensitivity to race differences. Both the friendship and choice of work partner scales of this study indicated race trends in the positive prejudice direction (significantly so in Study II). By finding slight amounts of negative Negro prejudice on such scales and large amounts of "belief prejudice," the studies of the belief theory of prejudice which have used those measures as key scales (see above for a listing of those studies) have tended to support the belief theory. In light of the present evidence, those studies must be interpreted with caution.

The data of both these studies have indicated that it is very possible for an individual to indicate negative Negro prejudice on several measures while indicating positive prejudice on others. That finding would tend to support the proposition that an analytic approach to the under- 
standing and definition of prejudice is most important. One expresses racial biases, not bias.

\section{Dimensions of Positive Prejudice}

When interpersonal relationships have permanent or formalized characteristics they take on meanings and implications different from those they have under less formal or permanent circumstances. Formality and permanence are often associated with the loss of life's degrees of freedom; when the outcomes of associations are uncertain, people are usually reluctant to bind themselves into formal or permanent relationships. Ties of kinship and location of residence are permanent or formalized conditions - they describe the only scales of these studies which reflected main effects for negative race prejudice. They reflect a reluctance by the subjects of these studies to enter into formalized or permanent relationships with Negroes (relative to their willingness with comparable whites).

This dimension seems equally applicable to the phenomenon of positive prejudice. Below is a list of the eight scales of Study I which indicated a difference between the high social desirability Negro and the high social desirability white conditions of at least half a scale point favoring the Negro, and of the eight scales of Study II which reflected the same mean difference between the two Negro stimulus persons and the two white stimulus persons favoring the Negroes. The studies to which the scales apply are indicated by the Roman numerals following each scale. The scales were arranged in this pattern to indicate the categories which seem to characterize them best.

\section{Informal association}

1. How much would you like this person if met? (I \& II)

2. Would participate with in a discussion (I \& II)

3. Would be partners with in an experiment (I \& II)

4. Would invite to my home (I)

5. Liking for working with on class project (II)

6. Would have as an intimate friend (II)

\section{Antisubordination}

1. Elect to political office (I \& II)

2. Accept as a leader (I \& II)
3. Treat as an equal (I)

4. Treat as a subordinate (I)

5. Admire the ideas of (II)

None of the scales of the first category binds the subject into permanent relationships from which he cannot easily escape. For whatever reason the Negro stimulus person is preferred over the white on that first grouping of scales, no irrevocable kind of recognition is offered, as might be the case in inviting the Negro to one's club or in cooperation in community affairs. None of the scales in that first group comes close to the formality or permanence of recognition of the kinship and neighborhood proximity scales, which indicate negative prejudice.

The second category of positive prejudice scales reflects another apparent dimension of positive prejudice - a declaration against the personal recognition of, or the sanction of, racial inferiority and a desire to demonstrate that conviction. All the items of the second category pertain to acts of exalting, or following, or putting the Negro stimulus person in a position so that he could be followed (electing).

Explanations for positive prejudice could take many forms, but whether positive prejudice is seen as the product of the desire to appear equalitarian, or of guilt reactions to negative prejudice, or of the feeling that a Negro of middle-class status has accomplished more than a comparable white person, a major concern must be whether such findings reflect anything more than socially acceptable responses which do not reflect true feelings. Within the present experiments there are several lines of evidence which suggest that the many instances of positive prejudice are more than insincere efforts to respond in socially desirable ways. If the tendency toward giving socially desirable responses had been a major factor in these data, it would be reasonable to expect that subjects would have been more uniformly positive in their evaluations of the Negro stimulus persons relative to the whites. That was not the case, several BD scales indicated negative Negro prejudice in both studies.

The paradigm of these studies gives the individual subject the opportunity to express negative or positive racial bias toward a Negro stimulus person without appearing prejudiced. That is, since each subject rated two entirely different stimulus personalities, one labeled $\mathrm{Ne}$ gro and one labeled white, he indicated little about his personal racial 
prejudice by rating the two persons differently. It is only when the four race-personality conditions are compared by considering the two subject groups together (each of whom saw only two of the four race-personality combinations) that race and personality variance becomes differentiable. Since the individual subject can respond to the Negro stimulus person in a socially desirable or undesirable manner without indicating anything concrete about his personal racial attitudes, it seems less likely that he would respond to race in a false manner.

It appears that the changing pattern and degree of racial prejudice in American life have carried many young people past the point of acting with equality on certain dimensions toward Negroes. Positive prejudice seems to be a pattern of the avant-garde — of that liberal element of campus society (at the very least) which is highly concerned with peace and social justice, and which demonstrates relative flexibility in patterns of living and thinking

\section{SUMMARY}

Two studies were conducted in order to investigate positive prejudice toward Negroes. By defining positive prejudice as favoritism toward Negro stimulus persons over white stimulus persons of identical personality descriptions, it was possible to compare patterns of Negro bias on a variety of measures. The results of Study I indicated that positive Negro prejudice was more likely when stimulus persons at the positive personality level were compared. The results of Study II indicated that dogmatism and rigidity and attitudes associated with authoritarianism are negatively related to positive prejudice. Dimensions of formality of relationships and antisubordination of Negroes were useful in understanding positive prejudice. The relevance of the results to the belief theory of prejudice are discussed.

\section{REFERENCES}

Adorno, T. W., Frenkel-Brunswik, E., Levinson, D. J., \& Sanford, R. N. The authoritarian personality. New York: Harper, 1950.

Byrne, D, \& McGraw, G. Interpersonal attraction toward Negroes. Human Relations, 1964, 17, 201-213.
Byrne, D. , \& Wong, T. J. Racial prejudice, interpersonal attraction, and assumed dissimilarity of attitudes. Journal of Abnormal and Social Psychology, 1962, 65, 246-253.

Davis, E. E ., \& Triandis, H. G. An exploratory study of intercultural negotiations. Technical Report No 26, November, 1965, University of Illinois, Contract NR 177-472, Nonr-1834(36), Advanced Research Projects Agency and the Office of Naval Research.

Hays, W. L. Statistics for psychologists. New York: Holt, 1963.

Insko, G. A., \& Robinson, J. E. Belief similarity versus race as determinants of reactions to Negroes by southern white adolescents: A further test of Rokeach's theory. Journal of Personality and Social Psychology, 1967, 7, 216-221.

Keniston, K. The sources of student dissent. Journal of Social Issues, 1967, 13, (3), 108-137.

Prentice, N. in The influence of ethnic attitude on reasoning about ethnic groups. Journal of Abnormal and Social Psychology, 1957, 55, 270-272.

Rokeach, M. The open and closed mind. New York: Basic Books, 1960.

Rokeach, M, Smith, P. W., \& Evans, R. I. Two kinds of prejudice or one? In M. Rokeach, The open and closed mind. New York: Basic Books, 1960.

Schuman, H., \& Harding, J. Prejudice and the norm of rationality. Sociometry, 1964, 17, 353-371.

Smith, G. R., Williams, L., \& Willis, R. H. Race, sex and belief as determinants of friendship acceptance. Journal of Personality and Social Psychology, 1967, 5, 127-137.

Stein, D. D. The influence of belief systems on interpersonal performance: A validation study of Rokeach's theory of prejudice. Psychological Monographs, 1966, 80 (8, Whole No 616).

Stein, D. D., Hardyck, J. A., \& Smith, M. B. Race and belief, an open and shut case. Journal of Personality and Social Psychology, 1965, 1, 281-289.

Triandis, H. G. A note on Rokeach's theory of prejudice. Journal of Abnormal and Social Psychology, 1961, 62, 184-186.

Triandis, H. G. Exploratory factor analysis of the behavioral component of social attitudes. Journal of Abnormal and Social Psychology, 1964, 68, 420-430.

Triandis, H. G., \& Davis, E. E. Race and belief as determinants of behavioral intentions. Journal of Personality and Social Psychology, 1965, 2, 715-725.

Warner, W. L., Meeker, M., \& Eels, K. Social class in America. Chicago: Social Research Associates, 1949.

Manuscript submitted June 1969. 